\title{
Wittgenstein and the Illusion of 'Progress': On Real Politics and Real Philosophy in a World of Technocracy
}

\author{
RUPERT READ
}

\begin{abstract}
'You can't stop progress', we are endlessly told. But what is meant by "progress"? What is "progress" toward? We are rarely told. Human flourishing? And a culture? That would be a good start-but rarely seems a criterion for 'progress'. (In fact, survival would be a good start...)

Rather, 'progress' is simply a process, that we are not allowed, apparently, to stop. Or rather: it would be futile to seek to stopit. So that we are seemingly-deliberately demoralised into giving up even trying.

Questioning the myth of 'progress', and seeking to substitute for it the idea of real progress - progress which is actually assessed according to some independent notpurely-procedural criteria - is a vital thing to do, at this point in history. Literally: life, or atleastcivilisation, and thus culture, may depend onit.

Once we overcome the myth of 'progress', we can clear the ground for a real politics that would jettison the absurd hubris of liberalism and of most 'Leftism'. And would jettison the extreme Prometheanism and lack of precaution endemic to our current pseudo-democratic technocracy. The challenge is to do so in a way that does not fall into complete pessimism or into an endorsement of the untenable and unsavoury features of conservatism. The challenge, in other words, is to generate an ideology or philosophy for our time, that might yet save us, and ensure that we are worth saving.

This paper is then a kind of reading of Wittgenstein's crucial aphorism on this topic: 'Our civilization is characterized by the word progress. Progress is its form rather than making progress being one of its features.'
\end{abstract}

Our civilization is characterized by the word 'progress'. Progress is its form rather than making progress one of its features. Typically it constructs. It is occupied with building an ever more complicated structure. ${ }^{1}$

${ }^{1}$ The quote continues: 'And even clarity is only sought as a means to this end, not as an end in itself. For me on the contrary clarity, perspicuity are valuable in themselves. I am not interested in constructing a building, so much as in having a perspicuous view of the foundations of typical buildings.' Culture and Value (ed. G. H. von Wright; transl. Peter Winch; Oxford: Blackwell, 1980), 7-8. 


\section{Rupert Read}

This piece is a reading of what I think is Wittgenstein's greatest aphorism on the topic of progress: 'Our Civilisation is characterised by the word "progress". Progress is its form rather than making progress being one of its features.' Somebody reading that aphorism superficially might think that what Wittgenstein is saying is that progress is a feature of our civilisation and isn't that just great? But that's exactly what he's not saying - it's the opposite of what he is saying - and I will aspire to bring that out.

Wittgenstein was very sceptical, as we shall see, about theidea of progress. And he thought that the way in which this aphorism was true reflected very badly on our civilisation.

In order to start seeing how and why, I want to turn straight away to another quote from Wittgenstein (in fact, from Nestroy), the epigraph for Philosophical Investigations: ${ }^{2}$ It is in the nature of progress that it is always less than it seems'. What is Wittgenstein telling us by putting this at the front of his great later work, the Philosophical Investigations?

Well, the standard professed reading of this aphorism, in so far as there is one-people don't often pay it a lot of attention, which is interesting and telling in itself-is that what Wittgenstein is saying here is that the progress between his own early work and later work is much less than it seems. And I am in favour of that interpretation of this aphorism.

But, on most readings of Wittgenstein, it is impossible to understand how to take that interpretation seriously. Most readings of Wittgenstein, at least until recently, have suggested that Wittgenstein had 'two distinct philosophies', and that the later was a massive advance on the former, which had been refuted.

I would like to go so far as to say that, in recent years, I think we have started taking seriously this remark of Nestroy's as the epigraph to the Investigations for the first time. And this has been part of the socalled 'New Wittgenstein' interpretation that I and others have developed, ${ }^{3}$ which suggests that it's a radical misunderstanding of Wittgenstein to think that in his early work he proposed a theory, and thenin hislater work he said, 'No, that theory is wrong', and pro' posed another theory, or even the-absence-of-a-theory as a new idol. ${ }^{4}$

\footnotetext{
2 Philosophical Investigations (London: MacMillan, 2009/1953).

${ }^{3}$ See my and Crary's edited collection, The New Wittgenstein (London: Routledge, 2000).

${ }^{4}$ On this last point, see Martin Stone's essay in my and Crary's (ibid)., 'Wittgenstein on deconstruction', and my own 'A no-theory theory?', Philosophical Investigations 29:1 (2006), 73-81.
} 
He didn't propose any theory in his early work; his early work was already dedicated to the complete overthrow of philosophical theories. And the progress between his early work and later work, in my view, is basically a (deep) question of style and presentation and depth and detail. ${ }^{5}$ And enriching, as he put it famously, our diet of examples, in a way that was not present in his early work, the Tractatus, where his diet of examples was very very thin. He was undernourished with examples in his early work, and that's one of the key changes between the early work and the later work, according to our 'New Wittgenstein' interpretation, which is also sometimes called the 'Resolute Reading' of Wittgenstein.

The idea is that Wittgenstein, throughout his life, was resolutely opposed to philosophical theorising, and resolutely determined to overcome the philosophical theories that he saw gripping contemporaries and antecedents, without replacing them with anything of the same form, or even with anything of the same form as the 'gap' which their passing seemed to leave.

So I believe that (t)his epigraph is intended by Wittgenstein as a way of introducing the Philosophical Investigations and saying, in effect, in advance prophylactical warning, 'Don't make the mistake of thinking that the progress I've made here on my earlier work is very great'.

ButIalsowant toputit toyou that thisepigraphis doing a lot more than that. I think it would be a mistake, a serious mistake, to see this epigraph as narrowly self-regarding on Wittgenstein's part. It's not just about his own work.

The transition from the Tractatus, his earlier work, to the Philosophical Investigations, his later work, and his thought that, 'You should try to see this as a case where actually, there is very little progress, much less has changed than might meet the eye', is intended by him, I believe, as an example. It's an example of a much broader phenomenon. It's an example of, if you like, the way in which we tend, drastically, and dangerously, and in a dubiously self-congratulatorily mode, to overestimate the progress that we have made as individuals, as a discipline, as a society, and as a civilisation.

Wittgenstein wanted to suggest, with regard to authors who are tempted say, 'In my early work I thought this and then I realised it was wrong and now I've got these brilliant new ideas to replace

${ }^{5}$ For detail, see my and Rob Deans's 'The possibility of a resolutely resolute reading of the Tractatus', in my and Matt Lavery's Beyond the Tractatus Wars (London: Routledge, 2011). 


\section{Rupert Read}

those old rubbish ideas with', that there is something dangerous about that attitude on their part. ${ }^{6}$

And in the same kind of way, he thinks that when we as a society say, 'In the old days we were primitive, and now we're modern and we've got all these brilliant ways of organising everything that shows so clearly how we've progressed, from the dark depths of our ancestors, from the 'Dark Ages", that we are engaging in self-backpatting behaviour of a dubious kind. (It's funny how people virtually never say, 'We're living in a dark age'. The 'Dark Ages' are almost always sometime long ago.)

Wittgenstein intends this epigraph (to Philosophical Investigations) to bring to our attention his own small progress, as an example of a much broader phenomenon of the way we're inclined to overestimate the nature of progress, and about how this is dangerous. About how the idea of progress - the tacit ideology, as I shall put it to you that it is, of progress - is, as he famously puts it elsewhere, a picture that holds us captive. He wants to help release us from this captivity. He wants to suggest that we need to be much more judicious in measuring or assuming or claiming progress.

Before I consider progress as a general unthinking societal ideology, and as a phenomenon that Wittgenstein thinks is less real than it seems, Iwant todwell just a moment more on Wittgenstein on progress in philosophy. So here's a third quotation from Wittgenstein:

'Philosophy hasn't made any progress? - If somebody scratches the spot where he has an itch, do we have to see some progress? Isn't genuine scratching otherwise, or genuine itching itching? And can't this reaction to an irritation continue in the same way for a long time before a cure for the itching is discovered?'

I think this is a wonderful way of - as Wittgenstein not-infrequently does - demystifying or puncturing the nimbus of grandiosity that we sometimes build around philosophy. He likens philosophy, the history of philosophy, to scratching an inch. This is quite a radical-disruptive-move to be making.

Most of the history of philosophy consists in scratching an itch. And of course scratching an itch can make it worse; it doesn't necessarily create progress at all. It can also, when at works, be at least

${ }^{6}$ My own view is that Wittgenstein himself did not succeed in fully overcoming this tendency in himself. See my essay in Beyond the Tractatus wars (ibid.), for explication. (In other words: I think that Wittgenstein in his later work became if anything slightly too hard on his early work.) But at least he drew our attention powerfully to the tendency.

7 Culture and Value, 86. 
temporarily satisfying. Well, that might be figured as a kind of progress. But, as he says, 'Do we have to see some progress?' Real progress in philosophy, for Wittgenstein, is in another register entirely; it doesn't consist in what we are inclined to think of as progress. Real progress is discovering a cure: no longer needing to scratch the itch. Or simply no longer itching. And those are what Wittgenstein did, or (atleast) that's what he thought he did, and I agree with him.

It's also-and this is very important - not just what he did in his later work and earlier work; it's also what many of his great predecessors had done. People such as Descartes, Berkeley, Hume, Kierkegaard, Nietzsche, Frege.

It's a mistake to think that what Wittgenstein thinks about these figures that came before him is that they're all almost idiots, or all to be simply jettisoned. He didn't think that at all. He thought these people were great deep thinkers, wrestling with great deep problematics. And he thought that at their best, unlike many of their interpreters and followers, they did actually succeed in offering clues towards a cure of the desire to philosophise.

I think it's clear how one can see this at moments in the work of people such as Nietzsche and Frege - I'll come back to them, shortly. Gordon Baker, one of my teachers, famously argued this in reinterpreting Descartes, alongside Katherine Morris. ${ }^{8}$ Cora Diamond, another of my teachers, has argued the same for Berkeley. ${ }^{9}$ I've argued the same for Hume. ${ }^{10}$ James Conant has argued the same for Kierkegaard. ${ }^{11}$ We 'New Wittgensteinians', one of the things we like to do is to go back into the history of philosophy and say, 'From a Wittgensteinian point of view, these people were not idiots; it's not that they were just down there primitively in the dirt and we've made this huge progress now'. No.

Very roughly: They were already seeking to do the very thing that Wittgenstein succeeded just a little bit better in doing. And it's not like he's completed the job either. People sometimes think, 'Didn't Wittgenstein end philosophy? Or thought he'd ended philosophy?'

${ }^{8}$ Gordon Baker and Katherine Morris, Descartes's dualism (London: Routledge, 2002).

${ }^{9}$ In the title essay of The Realistic Spirit (Cambridge, MA: MIT, 1991).

${ }_{10}$ See my "The new antagonists of "the New Hume": on the relevance of Wittgenstein and Goodman to the "New Hume debate", in my and Ken Richman's The New Hume Debate (London: Routledge, 2007).

${ }^{11}$ See e.g. his masterly 'Must We Show What We Cannot Say?' in The Senses of Stanley Cavell, ed. R. Fleming and M. Payne (Bucknell University Press, Lewisburg: 1989), 242-283. 


\section{Rupert Read}

No, he didn't think that and there are numerous places in his texts where you can see that he didn't think that. ${ }^{12}$ What he thought was that, when you were in philosophy seriously, you must be seeking in some sense to end the process or pain of itching. But he didn'tcomplacently or hubristically assume that he had arrived at that place where he no longer had any itches, nor that doing so could be achieved by any kind of frontal assault, any broadly 'linear' or 'progressive' method.

So, acrucial point: looking back on thehistory of philosophy, what we see when we look at the great philosophers at their greatest moments is something broadly similar. Look at Frege, for example, at his deepest, when he says things like 'The reader needs at this point in my work to give me a pinch of salt, there is something here that I want to say but I can't quite succeed in saying it'; ${ }^{13}$ or, at Nietzsche when he gets to the moment close to the end of the Genealogy of Morality (and in book five of The Gay Science) when he, as I see it, successfully shows us, in relation to the very people who he is criticising, Christian thinkers etcetera, that he is, in a way, an extreme example of that very same mode of thinking. ${ }^{14}$ He's trying to bring something to an end but it's very difficult to do so. This kind of 'real progress', this kind of cure, as opposed to just scratching an itch, is not achievable by aping science. Nietzsche is telling us that he has achieved far less progress than meets the eye over asceticism. Frege is telling us that he his new way of doing philosophy (that launched 'analytic philosophy') is far less securely founded than meets the eye, and that it is not (as most of his 'successors' have taken it to be) a new invulnerable quasi-scientific enterprise. This is great: for a philosopher to acknowledge their own limits, to push up-front their not having made a progressive bound, but having rather made a painful small and not-of-thekind-as-usually-understood shuffle forward beyond the greatness of what came before. For us to understand how Nietzsche has improved on what has gonebefore, we have to see the profoundlevelofthecommonality he has with his supposed enemies. For us to understand how Frege has improved on what has gone before, likewise.

${ }^{12}$ See e.g.Zettel (Berkeley: U. Cal. Press/Blackwell, 1967) section 447. Seealso my reading of 133 , a passage often (wrongly) adduced toimputean 'end of philosophy' philosophy to Wittgenstein: 'Thereal philosophical discovery', Philosophical Investigations 18:4 (1995), 362-369.

${ }^{13}$ See my reading thereof in Chapter 1 of my A Wittgensteinian Way with Paradoxes (New York: Lexington, 2013).

${ }^{14}$ I offer this reading in Chapter 10 of my (ibid). 
Science: the quintessentially progressive subject, or set of subjects. This is what a lot of my work in recent years has been about: How various subjects such as, most strikingly, the 'social sciences', but also philosophy itself, are subjects that do not progress as science undoubtedly does. Science progresses, most strikingly, for example, in the way that, as Thomas Kuhn famously describes to us: there is the process of 'normal science'. In which, what science consists of is essentially puzzle-solving, working away at a set of problems which are widely accepted, filling out a paradigm, filling out a theory which is already present and making it better, making it more accurate, filling in the holes in it. That's progress. That is a wayin which it makes good sense to talk about progress.

Butjust because science has been successful does not imply that other subjects can or (even 'ideally') should progress in the same way. And in particular, a great deal of the history of philosophy, especially in recent years, has been occupied by people thinking, 'Hell if only we could make our subject into a subject like science and progress like science does, wouldn't that be great?' And the answer is: no; it's a farrago, it's a disaster. This is one of the key things that Wittgenstein sought to show us. Philosophers have tried to progress typically by answering questions, metaphysical questions, epistemological questions, logical questions. Answering questions is the right thing to do when it's clear that there are questions to ask, and that the questions have been framed aright. Just what isn't ever clear, in philosophy.

This - scientism, the idea that every discipline should proceed and progress by answering questions, solving puzzles - isn't the way Wittgenstein taught us to make any real progress in philosophy. On the very contrary: one needs rather to interrogate the questions, to question the questions. And to interrogate the tacit ideologies that generate these questions in our mind. For example, the ideology of scientism itself, the ideology that says that: every real problem should be answered by the methodology of science. Scientism is a justification, a would-be justification, for technophilia, for the dogmatic love of technology, and for the ideology of progressivism that I am going to talk more about in a moment.

Actually, the justification doesn't work even if scientism were right (which it isn't), because it doesn't follow from the fact that there is scientific progress, that there is in the same sense technological progress. Scientific progress is about us coming to know more about the world; technological progress is about us being able to do more to the world. But just because we can do more to the world, it doesn't necessarily mean that we ought to do more to the world. 


\section{Rupert Read}

Barring certain extreme cases where questions of ethics arise, no-one can really complain - there is nothing to be said against it - when scientists learn something they didn't know before; but when a new technology is created it's always an open question whether we should complain. I am going to suggest that sometimes we should and that sometimes it is essential, indeed, for us to do so.

In this way, and this is a central idea of my lecture, we need an independent criterion to assess technological progress by means of. Just because a new technological innovation has occurred, it does not mean that we should really describe that as progress.

So, as Isay, in the Twentieth and Twenty-first century in particular, philosophy, especially in the English-speaking world, has tended to embrace one form or another of scientism unfortunately. Wittgenstein has mounted a heroic rear-guard action against scientism, as manifested especially in so-called analytic philosophy, a 'dis' cipline' in which we make progress; we make progress allegedly on the mind-body problem, on the problem of our knowledge of the socalled external world; and so on and so forth.

Let me attempt an adaptation of the aphorism with which I began, applying it now specifically to our subject of philosophy. I put it to you that Wittgenstein could have said about that specific topic, 'Our discipline is characterised by the word progress; progress is its form, rather than making progress being one of its features.' And in saying that, he would have been mounting the most powerful criticism of our discipline, philosophy, as it views itself. For that is an incoherent way of understanding what philosophy is, butit is the dominant understanding of what philosophy is in a country like this, or in the United States, today.

So as I say, and as I said earlier, think about what Wittgenstein is saying about progress as being about his own philosophy, and about philosophy in general, but about these things as an example of a much broader phenomenon, a phenomenon that effects our entire civilisation. When people say things like, 'You can't stop progress' they have in mind exactly a version of progress that Wittgenstein is criticising, when he says that 'our civilisation is characterised by the word progress; progress is its form, rather than making progress being one of its features.'

Such peopleareimplyingthereis noneedfor, thereisnoroomfor, an independent criterion by means of which we can assess the degree, or otherwise, to which there has been progress. Progress is what our society does by definition. (What the engines of technological and economic change do. The accumulation of information, knowledge, power.) And I want to counterpoise against that the idea of real progress. 
But before I tell you more about what real progress would mean, let me dwell a little bit more on the way that the term 'progress' generally functions when people say things like 'We can't stop progress', and what is wrong with this. Progress in this sense is, among other things, crucially, I put it to you, synonymous with 'growth'; or, more specifically, economic growth (growth in 'GDP'). And with technological expansionism, and with the concept of 'development', as in, 'sustainable development'; as in, the idea that when we have a load of new houses being built, on a flood plain, or in a green belt, that's development - after all, that's simply what it's called.

There is a new 'development' going up around Cambridge, say. Is that really a development? You can't ask that question. Because development, by definition, is what 'development' is. 'It is progress'; that is what we're told without it even being needed to be made explicit. The idea is that these things are somehow inevitable and that destiny says that we are moving ever onward and upward, that there is no end to this process. Again, this is what Wittgenstein is criticising in the aphorism which this lecture is focussed around reading. And I want to say that he is right.

Other voices who are pointing in the same direction as me at the present time in this country include the interesting, quasi-conservative, philosopher, John Gray, who is I think right to challenge the myth of progress, which he has done explicitly. I will return to Gray below. Mayer Hillman, Emeritus Fellow of the Policy Studies Institute, is another, arguing, at the present time, that the likelihood now is that our children and our grandchildren will inherit worsening conditions of life relative to ourselves, which is not something that we're used to. This is a new phenomenon; it doesn't fit the ideology that we've been brought up with.

Almost certainly, by the way, this point of worsening has already begun. It's very hard to measure these things - there's a philosophical question about the extent to which measurement as such is a worthwhile aspiration, when it comes to happiness, etc. . But, in so far as these things can be measured, it looks as if there is some evidence to believe that things have got worse in countries like this and the United States and much of Europe. Since about the 1950s, and certainly since the 1970s, it appears that things have gradually started getting worse. ${ }^{15}$ 'In spite of' the economy continuing to grow, and new technologies continuing to become available.

15 See e.g. http://news.bbc.co.uk/1/hi/programmes/happiness_ formula/4771908.stm. 


\section{Rupert Read}

We have, I believe, tojunk the idea of progress as inevitable. Any hard won real progress has to be real. We need an independent criterion to measure it by.

Because technological progress is not an independent criterion. Technological progress is simply what occurs 'naturally', if scientists and engineers and investors and so on are allowed and facilitated to act as they tend to, in a society like ours. Technological progress is simply what our society does. This is what Wittgenstein is saying. But that by no means implies that such progress is always to be welcomed.

What about Gross Domestic Progress? Does an increase in GDP'economic growth' - connote a measure of (real) progress? Can it be an independent criterion by which to measure our society? Of course not, for the reasons I've given: An increase in GDP is simply what our economy is expected to do 'naturally'. It doesn't actually mean that things really are getting better: for lots of things increase GDP while actually making things worse. A classic example, so incredible that it serves in itself as a kind of reductio ad absurdum of economic-growthism, is the apparent fact that the judgement of expert economists is that the most-harmful-ever oil spill, the BP Gulf of Mexico disaster of 2010, was actually 'beneficial' to the economy, increasing GDP... ${ }^{16}$

So: What might such an independent criterion actually be? Well, as implied above, perhaps something like well-being. Do people actually have a stronger sense of well-being than they did before? One might generalise and talk about the flourishing of all beings, including nonhuman beings. Are we the only species that matters? And indeed future people, our descendants: they matter, too. ${ }^{17} \mathrm{I}$ believe that a return to one-planet living, to living as if we have one planet - at the moment we're living in this country as if we have about 4; so that's about 3 more than area actually available - is not only nonnegotiable; I believe that such a return to one-planet living must be part of the independent criterion I am referring to, by means of which we assess whether we are actually making progress. Because I don't see how we can be making progress, if we are overshooting the limits to growth and eating into the life-support-conditions of our children.

I want to put it to you that real progress probably requires the opposite of most of what is currently called progress. It probably

${ }^{16}$ See e.g. section 6 of http://useconomy.about.com/od/suppl1/tp/ BP_Oil_Spill.htm.

${ }^{17}$ See on this my 'On Future People', in Think 10:29, 43-47: http:// journals.cambridge.org/repo_A83AqV93. 
requires, for example, an end to 'economic growth'. At this point people often say, 'But then, what are you going to do about all the peopleliving in poverty?'

In order to solve poverty in a world where we are awash in riches and wealth, which most of us are experiencing in this country at a level of all-time historical decadence, where there are people who are poor, surely the answer is that the rich need to give up a bit of what they have and share it with them. Once that's done the need for growth is (to say the least) by no means clear any longer.

Sometimes, people recently say things to me in objection along the following lines: 'Ah yes, but haven't you read Thomas Piketty? The great Thomas Piketty has told us that the world is dreadfully unequal and becoming more unequal'. Piketty's dead right about that. But Piketty has also suggested that a key part of the problem is that we don'thaveas much economic grow th as weused to. And my response to Professor Piketty at that point is to say, 'If you're really wanting to inherit the mantel of Karl Marx, wouldn't it behove you to talk rather less about growth and rather more about sharing? ${ }^{18}$

Progress, growth: these are obstacles to our thinking. They imprison us. We need freedom from them. We need what Wittgenstein called 'liberation' from them, unless we radically reconceive what they are. We have, in particular, to give up the idea that these things are linear, or that they are endless, or that they are intrinsically desirable. Now there is a certain sense in which there is a linearity to progress; there is a wonderful fact about human beings, which is not true of most other animals - I say 'most' because it is now clear that there are modicums of what we call culture present in the lives of some of our primate cousins, including chimpanzees, bonobos and some monkeys, and in many cetaceans. The wonderful fact is that we as human beings, to a much greater extent than they, are historical beings. This is a marvellous thing, that we can learn and in some ways we always do learn from our mistakes in history, from what happened before. Often of course, not as much as weshould (or nothingatall; or less than nothing!). I.e. this process is not guaranteed.

Think of theMiddle Ages where it appears that, while welearned some things, we also lost quite a lot of knowledge. There was a gradual loss of knowledge, texts gradually deteriorated as they were copied etcetera etcetera... We can lose knowledge. And of course it

${ }^{18}$ My full response to Piketty can be found here, in Radical Philosophy 189: 'Green economics versus growth economics', https://www.radicalphilosophy.com/commentary/green-economics-versus-growth-economics. 


\section{Rupert Read}

can go much further than that; societies can collapse. ${ }^{19}$ And in fact what we find if we look at societies that have collapsed, is that most often they've collapsed if they've sought to progress endlessly...

If we turn to the term 'growth', then of course one thing which is important to notice is that the term growth is a term that is taken from

a biological original meaning. Growth in biology is something organic. It involves circular rhythms: something grows, it matures, it decays, it dies, it decays completely, it becomes raw material for something else to grow. When we think of it in that way, as a lifecycle, one question one might ask is, 'Does that mean that economies are doomed to collapse?' I don't think they're doomed to collapse, I don't think we're doomed to collapse. But we have to think beyond the box of endless growth if we're going to escape that doom. And that economies are (hopefully) not doomed to collapse is itself an indicator of the serious limits and hazards of the 'growth' metaphor...

And we should note furthermore that that the very idea of economic growth is a kind of bastardisation, a dangerous projection of biology onto the inorganic. Because it fantasises the economy as an organism, while trying to extricate from the idea of being an organism the idea of it achieving any kind of maturity and being subject to any kinds of limits. The ideology of endless growth is a profoundly anti-biological ideology, and this is a profound problem.

Now in the past, when societies have collapsed the people who survived those collapses, if any, have learnt from those collapses; they've learned how to be more 'sustainable', as the current jargon has it. ${ }^{20}$ Tim Flannery, explains this process wonderfully in his book The Future Eaters. ${ }^{21}$ He explains how we can resolve the paradox that, on the one hand we want to say indigenous peoples are these wonderful paragons of ecological virtue, and on the other hand, indigenous peoples destroyed all their mega-fauna. Both are true.

Basically the process, as Flannery describes it, is that typically what's happened in our deep pre-history is that indigenous peoples, our deep ancestors, have destroyed many of the conditions for their own lives. And have then learned from that destruction and have

${ }^{19}$ See on this Jared Diamond's important book, Collapse (London: Penguin, 2011).

${ }_{20}$ For my objections to that jargon, see the section on "'Sustainability"?' in my chapter on 'Post-growth common-sense' in John Blewitt and Ray Cunningham's The Post-Growth Project (London: London Publishing Partnership, 2014).

${ }^{21}$ The Future Eaters (Kew: Reed Books, 1994). 
learned ecological wisdom that we then sometimes found them with when we encountered them.

The problem of course is that wecan't afford tolearn from our own collapse, because if our own collapse occurs, it will be global and probably completely terminal. We must instead take a fundamentally precautionary attitude, we must learn from the mistakes of others before committing mistakes of the same gravity. This requires a giving up of the delusions of 'endless progress', 'growth', 'development'before it's toolate. We mustlearnfrom their collapses and ecological disasters, not our own.

And this brings us to what is the terrible irony of the ideology of progressivism (and similar ideologies such as modernism): it is thoroughly out of date. It might have been an appropriate ideologyin the eighteenth century or the nineteenth century - that is something we can debate-but it is not, now. The one fundamental way in which modernists are not modern is in regard to the relevance now of their own ideology! One fundamental way in which progressivists are not entitled to the term 'progressive' at all is that they don't understand how real progress now would mean precisely giving up the delusion of progressivism... It is paradoxical but true: progressivism is a defunct, out-of-date ideology. The idea that we must always be more modern is itself thoroughly past its sell-by-date.

This brings us to the vexed and vexing question of Wittgenstein and his relation to conservatism. There is a famous essay by J.C. Nyiri, 'Wittgenstein's later work in relation to Conservatism'; ${ }^{22}$ it caused an academic storm many years ago now. Because many people, and I think rightly, were concerned at the implication in the essay, that the implication of thinking through Wittgenstein's thinking, in something like the way I've done, led one to some very pessimistic and problematically politically-conservative conclusions.

Wittgenstein was quite culturally pessimistic. And there are other things that he did have in common with conservatism, and I think rightly so. I think that there are things that conservatism has got right. Most crucially the resistance to theory in conservatism. The resistance to the idea you can have a grand plan for completely remodelling society from the ground up. An idea which is fundamental to many forms of socialism and communism. An idea which is also found on the radical right in people like Hayek - Hayek in this way

${ }^{22}$ In Anthony Kenny \& Brian McGuinness (eds), Wittgenstein and His Times (University of Chicago Press, 1982). 


\section{Rupert Read}

is not a conservative as indeed explained in his famous essay, 'Why I am not a Conservative. ${ }^{23}$

Insofar as conservatism resists the delusional ideology of progress, then Wittgenstein and I are for it. But I think it is wrong to think Wittgenstein is a conservative if by 'conservative' one means anything at all like what we have in this country that is called the Conservative Party. Because the Conservative Party in this country has basically nothing whatsoever to do with conservatism anymore. The Conservative Party is a fundamentally neoliberal party. It is committed to endlessly more growth and 'modernisation', as well as to what it would claim as fiscal rectitude before all else.

And also we should remember that Wittgenstein was profoundly attracted by socialism and by communism, at least as profoundly attracted to them as he was by conservatism-the same is true of me. ${ }^{24}$ What we have to do, I believe, is try to find out, using something like the independent criterion that I sketched a little earlier, what is living and what is dead in the ideologies that we have inherited. Once we dispense with the delusional ideology of progressivism, of growthism, and once we dispense with developmentality, ${ }^{25}$ what is left?

Well let's quickly look then at the great ideologies that we have inherited and see how they fare on this score. So, take conservatism, represented today in this country by John Gray and Roger Scruton although I would say that unfortunately both of those thinkers are still not conservative enough, in the sense that they've both been infected, in my view, to some considerable extent, by neoliberalism (They have, that is to say, too great a prejudice in favour of 'the free market'). Conservatism, gets right, as I say, a fundamental resistance to theory, and a belief that there is something in our historical institutions that is worth preserving -in institutions, for example, such as the common law, in community, and of course in advocacy of conservation.

This is what I believe is living in conservatism. What is dead in conservatism, is its apologia for elites, its apologia for privilege, in particular its apologia for inherited privilege. None of these are tenable any more I think in our time today. A time which is (or

${ }^{23}$ Found as a post-script to his The Constitution of Liberty (London: Routledge, 1960).

${ }^{24}$ For detail, see my 'How ecologism is the true heir of both socialism and conservatism': http://blogs.lse.ac.uk/politicsandpolicy/how-ecologism- isthe-true-heir-of-both-socialism-and-conservatism/.

${ }^{25}$ On which, see Debal Deb, Beyond Developmentality (London: Earthscan, 2009). 
rather: aspires to become), profoundly-rightly I believe, a democratic one.

What about socialism? What is living in socialism? What I think is living in socialism is its fundamental idea of the social and of society, and tied in with that, the great dream, the great aspiration, the great goal: of equality, of human equality, as something to realise. (This connects directly with the importance of meaning democracy thus, of democracy in the workplace - and with the placing centrally of the social, of society.) What is dead in socialism, as I already implied, is its ambition for a grand overarching plan that can reconstruct everything from the ground up. As was shown to disastrously fail, in the times when it was, to some extent, tried in Russia and other countries.

And liberalism? What is living in liberalism is the idea of intellectual freedom, which is an idea profoundly important for Wittgenstein when he talked about the absolute importance of finding liberating words, of trying to liberate our minds from the ways in which they were held captive by inherited ideologies, which most of the time we are not even aware of.

And whatis living in liberalismalso, is theimportance of civiland political liberties.

But what is dead in liberalism, and in its bastard child which is now ruling us, neoliberalism, is individualism, which has been a profound disaster for our world, a profound wrong direction that we've moved in. And in so far as individualism triumphs, then there will be no future for the human race. And this can be connected with Wittgenstein's opposition to philosophical scepticism and to solipsism I believe; I've written on this elsewhere. ${ }^{26}$ There is, in Wittgenstein's philosophy and in the philosophy of some other great philosophers, some of whom I mentioned earlier, material for a profound resistance to the individualism which is a dominant and unquestionedideology of our time.

Something I like to do in my classes sometimes - I admit, it's a little bit cruel - is to say to students, 'What do you think is the most important thing about you?' and very quickly someone will say, 'It's that I'm an individual'. And then often what will happen is that somebody else in the class will say 'Yes, it's the same for me!' And then they'll sometimes get swiftly to the point where

${ }^{26}$ See Chapter 8, 'Swastikas and Cyborgs: The Significance of PI 420', of my AWittgensteinian Way with Paradoxes (Plymouth: Lexington Books, 2013), for a Reading of Wittgenstein's Philosophical Investigations as a 'war book'. 


\section{Rupert Read}

somebody will say 'We are all above all individuals', which some of you may recognise is a 'quote' (sic.) from a famous movie, The Life

of Brian: 'We are all individuals'. 'So the thing about you that most quintessentially sums up who you are is that you are all individuals?', I ask; and they all shout, in unison, in earnest, 'Yes!' I've really done this, quite often, and it's frightening how easy it is to do.

This is a disastrous feature of our times. We havenever been individuals. We are mammals, we are quintessentially social animals, and linguistic animals. Moreover, we are in fact, of course, far more en-

tangled than we've ever been before. Globalisation, thought through properly, ought to be the final death knell of the individualistic fantasy that lies at the heart of liberalism.

I suggest that we try to put aside what is dead in conservatism, in socialism, and liberalism, and bring together what is living in them. And bring together all of them under the banner of what's been called in recent years ecologism. An ideology, a philosophy that takes as its fundamental starting point the truth that we now, even if we possibly didn't have to before (though Tim Flannery and Jared Diamond would beg to differ), must take seriously that we are all completely beholden to our ecological conditions of possibility. That has to be the starting point and the ending point, the ground, for all of our political and philosophical thinking.

Let me reciptulate. 'You can't stop progress', we are constantly told. But what is meant by 'progress'? What is progress toward? Is it progress toward human flourishing, as Aristotle would have it? Is it towards wisdom, as Socrates would want? Towards a culture, not just a civilisation? Wittgenstein says, 'Ourcivilisation is characterised by the word progress.' There is another famous aphorism where he says, 'We have a civilisation; one day we may have a culture. ${ }^{27}$ For Wittgenstein 'civilisation' wasn't a very positive term, not as positive as in the famous quip of Gandhi's on western civilisation. Wittgenstein believed that our having something that we could call honorifically a culture is something that we should aim attain; and we have not attained it yet. He thought this partly because of the extent to which he saw our society has been dominated by scientism. And was, very worryingly, becoming more dominated by it, notless.

If progress was towards Aristotle's goal, or Socrates', or Wittgenstein's, that would be great. That would be real. But that very rarely seems a criterion for how the word 'progress' is actually typically applied in our society today.

${ }^{27}$ Culture and value, 64 (my translation). 
In fact, of course, one could have a more basic starting point. Before we even get to thinking about human flourishing, the flourishing of other beings, attaining wisdom, creating a culture out of our civilisation, it would be good to be at least reasonably confident that our civilisation was going to survive the next hundred years. But we cannot be confident of that. We can be less confident of that, the less we are prepared to give up on the ideologies of 'progress' and 'growth'. In our society, progress - and similarly growth - are taken for granted. They are the accepted 'wisdom' (sic.) of our media, our politics, our economics. We are suffering from the complete hegemonic taking-for-grantedness of the goal of economic growth - although we're finally starting to see a few little chinks in it now, ${ }^{28}$ and I'm hoping to create another one here.

'Progress' or 'growth' are simply a process that we are not allowed apparently to stop. Or that it would be futile to try to seek to stop, so that we are seemingly deliberately demoralised into giving up on even trying. We are prevented from thinking that we might even try. Questioning the myth of progress and concomitant myth of economic growth, and the basically synonymous myth of development is then a great task for intellectuals in our time.

Let me just take a moment on 'development', for it's such an unbelievably awful hubristic idea. What they tell us is that we live in a developed country and that there are all these other countries in the world that are 'developing'. So what we're supposed to believe is that all the other countries in the world are trying to, and ought to try to, aspire to be like us. As if we've arrived at the end of history and they are still in somekind of mini-dark age.

Moreover, what this idea of us being developed occludes is the point that we are endlessly continuing to develop, i.e: creating more and more 'development' - building over more and more of the green belt, ripping things down, putting things up, ${ }^{29}$ with everincreasing speed, ${ }^{30}$ everything allegedly getting better and more modern and so on all the time. In that sense, it is very obvious that

\footnotetext{
28 To mention one example, it is worth looking at Bhutan's goal: http:// www.grossnationalhappiness.com.

${ }^{29}$ The quotation that I have employed as an epigraph for the present essay includes this telling sentence: 'Typically, it [our 'progressive' civilization] constructs'. For Wittgenstein, building was not to be equated with progress. It might be (look say at the house he built); but often it was a substitute for thinking, for looking, for attending, for describing, for pausing, for dwelling.

${ }^{30}$ Think for instance of the untenable 'life-cycle' of mobile phones, today.
} 


\section{Rupert Read}

we are, even on their own terms, a developing country. ${ }^{31}$ So we're a developing country in that sense; but no, we're apparently a developed country. This is a profoundly dangerous self-contradictory ideology, an ideology which was created in its explicit form essentially by powerful Americans in the wake of the Second World War, in order to try to reinforce the system, which they were determined to remain at the heart of as decolonisation etc. happened. ${ }^{32}$

Questioning the myth of progress and growth and development, and seeking to substitute for it the idea of real progress, progress which is actually assessed according to some independent, nonpurely-procedural criterion, is a vital thing to do at this point in history. Literally life, or at least civilisation and the chance of culture in the future, may well depend on it. Sanity certainly depends on it. It is literally insane to seek to grow forever.

Understanding this creates, as I have sought to make clear, some difficulties for the Left in politics because it brings into question the catch-all understand of leftism as 'progressive'. It brings into question absolutely directly the ideology of 'productivism', which has historically been central to socialism: the dominant concept in socialism has typically been about making things, converting more and more of the earth into capital and into products for the masses. What I've been doing radically brings into question whether being 'progressive', in this sense, is actually a good thing.

Once we overcome the myth of progress, we can clear the ground for a real politics that would jettison the absurd hubris of liberalism, of individualism, and of much leftism. And would jettison the extreme Promethianism and lack of precaution endemic to our current pseudo-democratic technocracy.

The challenge is to do so in a way that does not fall into complete pessimism. I am by no means seeking to foment despair or a cynical spectatorial stance: what I'm hoping to do is open up space in which we can actually think what the alternative might be to all of this. The challenge, as I say, is to do what I'vejust described in a way that does not fall into complete pessimism, nor into an endorsement of the untenable features of conservatism. Most crucially, its apologia for elites and hierarchies.

The challenge, in other words, is to generate an ideology or philosophy for our time that might yet save us and ensure that we are

${ }^{31}$ Iowe this point to Jonathan Essex: see his important essay on 'How to Make-Do and Mend our economy', in Blewitt and Cunningham (op.cit.).

${ }^{32}$ For detail on this, see Wolfgang Sachs (ed.), The Development Dictionary (New York: Zed, 1992). 
worth saving. That we don't just have bare life, but rather flourishing, a culture, wisdom. This is what ecologism, seeking to integrate conservatism, socialism and liberalism - what remains of those, what is not dead in them - and to put them on a sound foundation of oneplanetliving, might offer us.

In conclusion, then. For Wittgenstein, 'progress' is not a feature of the main current of European/American civilization, but its form. That is to say: It is regarded as sufficient justification for any technological or economic innovation, to say 'That's progress'. Or 'You can't stop progress.' There is no possibility (or at least, has not been until very recently) endemic to the main cultural traditions of the West in recent centuries of questioning whether these changes really are progress. 'Of COURSE' they are. The only question is how they are to be best used. (Thus John Rawls for instance, the leading philosopher of contemporary liberalism, treats technology as a 'standing resource' for humanity, and treats the Earth the same way. There is no question of whether or not we might have fundamentally the wrong attitude to these things.)

For greens, the same is true as for Wittgenstein, on this point. That is to say: greens take issue with the mainstream, in that we ask, heretically, whether many of the changes that we have undergone or are undergoing are really progress. Is it really progress for instance to have built (as Wittgenstein figures it) an ever more complicated societal and industrial structure? Perhaps globalisation, and longer and longer supply lines, are not progress. Is it really progress, in the ' $\mathrm{de}^{-}$ veloped' world (a hubristic term that, as outlined above, needs in any case to be severely interrogated) to have more and more income and wealth, while happiness levels decline and the future itself is bankrupted?

And so this lecture can be heard, and I hope you are able now to hear it, as a kind-of reading of what I've argued is Ludwig Wittgenstein's (most) crucial aphorism on this topic:

'Our civilisation (note not culture, 'our civilisation', what we actually have, which is profoundly problematic) is characterised (and this is a central feature of that problematic) by the word progress; progress is its form, rather than making progress being one of its features.' If we were to bring in an independent criterion to say what progress, real progress, actually was, a criterion that we cannot just take for granted, that doesn't just go without saying and escape interrogation, then we would be changing from that situation. Progress then would potentially be a feature of our society, and this would be a good thing; whereas at the present time it is our society's form, and this is a bad thing. 


\section{Rupert Read}

But we cannot take for granted, as I've sought to explain, that real progress will be or has been achieved. We are vulnerable creatures, profoundly vulnerable social beings,${ }^{33}$ and our hubristic breaking of the limits to growth is making us more vulnerable every day. In this context, Wittgenstein's wisdom on the unwisdom of the ideology of progress is philosophy that our time most profoundly needs.

In the darkness of this time, Wittgensteinian thinking is a light that can give us direction.

University of East Anglia rupertread@fastmail.co.uk

${ }^{33}$ This, again, conservatism gets right. 